Journal of Linguistics

http://journals.cambridge.org/LIN

Additional services for Journal of Linguistics:

Email alerts: Click here

Subscriptions: Click here

Commercial reprints: Click here

Terms of use : Click here

\title{
Language against the odds: the learning of British Sign Language by a polyglot savant
}

GARY MORGAN, NEIL SMITH, IANTHI TSIMPLI and BENCIE WOLL

Journal of Linguistics / Volume 38 / Issue 01 / March 2002, pp 1 - 41

DOI: 10.1017/S0022226701001220, Published online: 25 April 2002

Link to this article: http://journals.cambridge.org/abstract_S0022226701001220

How to cite this article:

GARY MORGAN, NEIL SMITH, IANTHI TSIMPLI and BENCIE WOLL (2002). Language against the odds: the learning of British Sign Language by a polyglot savant. Journal of Linguistics, 38, pp 1-41 doi:10.1017/S0022226701001220

Request Permissions : $\underline{\text { Click here }}$ 
J. Linguistics 38 (2002), I-4I. (C) 2002 Cambridge University Press

DOI: IO.IOI7/So02222670IOOI220 Printed in the United Kingdom

\title{
Language against the odds: the learning of British Sign Language by a polyglot savant ${ }^{1}$
}

\author{
GARY MORGAN \\ University College London \\ NEIL SMITH \\ University College London
}

IANTHI TSIMPLI

University of Cambridge and Aristotle University of Thessaloniki

BENCIE WOLL

City University, London

(Received 23 June 2000; revised I8 May 200I)

In this paper we report on our attempt to teach the polyglot savant Christopher (' $\mathrm{C}$ ' hereinafter) British Sign Language (BSL). BSL presents $\mathrm{C}$ with a novel challenge in the use of hand-eye coordination, while at the same time offering him the linguistic ingredients he is obsessed with. Despite his deficits in key areas of intellectual ability, communication skills and visuo-spatial cognition, $\mathrm{C}$ has developed a working knowledge of BSL through processes of circumvention, adaptation and invention. As a form of control, we taught BSL to a comparator group of talented second-language learners. We do not discuss this comparison in depth here (see Morgan et al. in preparation) but refer to some of the test scores as a guide to how normal a sign learner $\mathrm{C}$ is.

Results from formal tests of C's linguistic knowledge, and observational study of his developing communicative ability in BSL, are analysed and described. These results illuminate the structure and use of BSL, highlighting the important role of visuo-spatial cognition in its acquisition and manipulation.

[I] Aspects of this research have been presented at the Theoretical Issues in Sign Language Research (TISLR) conference at Gallaudet University (July I998); at the Texas Linguistics Society Conference at the University of Texas at Austin (February 2000); at the Linguistics Association of Great Britain meeting at University College London (April 2000); and at the TISLR conference at the University of Amsterdam (July 2000). We are indebted to the audiences at all these venues, to Annabel Cormack, and to two anonymous $J L$ referees for their contribution. We are particularly grateful to Frances Elton and Ann Sturdy for their invaluable help with the project. We would also like to express our thanks to the Leverhulme Trust who, under grant F.I34AS, have supported our work on Christopher for a number of years, and to John Carlile for helping to make it possible. Our deepest debt is to Christopher himself and to his family, who have been unstinting in their support and cooperation. 


\section{G. MORGAN, N. SMITH, I. TSIMPLI \& B. WOLL}

Our findings support the assumption that the organisation of knowledge of language is largely modality independent, whereas the exploitation of specific grammatical devices is language and modality dependent. $\mathrm{C}$ has attained a certain level of linguistic competence in BSL, and his performance in the language is largely in conformity with his previously established mixed profile of abilities and disabilities.

\section{INTRODUCTION}

In earlier work (see Smith \& Tsimpli I99I, I993, I995, I996, I997; Smith I996; Tsimpli \& Smith I993, I995, I998; O'Connor et al. I994), we have documented the unique language learning abilities of a polyglot savant Christopher (C). C exhibits a striking dissociation between his linguistic and non-linguistic abilities. Despite living in sheltered accommodation, because his limited cognitive abilities make him unable to look after himself, $\mathrm{C}$ can read, write, translate and speak (with varying degrees of fluency) some 20 to 25 languages.

This linguistic talent is in sharp contrast with his general intellectual and physical abilities. As a result of a limb apraxia, he has difficulty with everyday activities such as shaving, doing up buttons, cutting his finger nails, or hanging cups on hooks. Additionally, he has a visuo-spatial deficit, which makes finding his way around difficult. However, although $\mathrm{C}$ is quite shortsighted and (probably) astigmatic, his prowess at 'finger-spelling' (the representation of the alphabet using configurations of the hands) shows that this condition need have little effect on his ability to understand sign. Fingerspelling is made up of small, fast movements of the fingers and hands in a relatively restricted sign space, and $\mathrm{C}$ was almost perfect in his recognition of finger-spelled names produced at normal signing speed, indicating that he should be able to see the details of normal signing without difficulty. Further, while the diagnosis has never been made clinically, it is reasonably clear that $\mathrm{C}$ is mildly autistic: he fails some, but not all, false-belief tasks, and he has some of the characteristic social manifestations of autism (see Baron-Cohen I995). He typically avoids eye contact, fails to initiate conversational exchanges, and is generally monosyllabic. (For discussion, see Smith \& Tsimpli I995, and especially Tsimpli \& Smith I998.)

In this paper we deal specifically with the linguistic aspects of C's learning of BSL, while taking note of the influence of his limb apraxia and autism. We explore in more detail the role of apraxia and autism in his learning of BSL in Morgan et al. (2002).

\section{Christopher's PSyCholinguistic PROfile}

In this section we flesh out the impressionistic overview given in the introduction with a more detailed presentation of C's various abilities and disabilities, including a discussion of his apraxia and visuo-spatial deficits. C 
scores relatively low on measures of non-verbal (performance) intelligence, as opposed to measures of verbal intelligence. This is indicated explicitly in (I) (summarising and correcting Smith \& Tsimpli I995:4-5), where the different figures show his performance on different occasions (the average is in each case I00).

(I) Raven's matrices:

[Administered at ages I4 and 32]

Wechsler Scale - WISC-R, UK:

[Administered at age I3.8]

Wechsler Adult Intelligence Scale:

[Administered at age 27.2]

Columbia Greystone Mental Maturity Scale:

[Administered at age 29.2]

Goodenough Draw a Man Test:

[Administered at ages I4 and 32]
$75 \quad 76$

42 (performance)

89 (verbal)

52 (performance)

98 (verbal)

56

$40 \quad 63$

In a multi-lingual version of the Peabody Picture Vocabulary Test, administered at age 28 (O'Connor \& Hermelin I99I), C scored: English I2I, German I I4, French I IO and Spanish 89.

The preference for the 'verbal' manifest in these data is reinforced by C's test results on variants of the Gollin figures test (Smith \& Tsimpli I995: 8-I2), on which he was strikingly better at identifying words than objects. Similarly, on the Warrington (1984) face/word recognition test, he scored between the

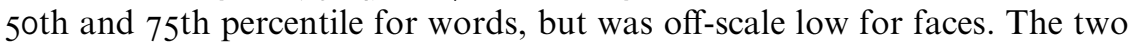
sets of figures in (2) show his performance on two applications of the test some 30 minutes apart: ${ }^{2}$
(2) Faces: $32 / 50$
Words:
$47 / 50$
$27 / 50$
$48 / 50$

Some of the differences in C's achievements on 'verbal' and 'performance' tests are likely to be a function of his apraxia. On an adaptation of the Boston Diagnostic Aphasia Examination (BDAE, Goodglass \& Kaplan I972, described in Poizner et al. I987), where the subject has to follow instructions such as 'show me how you chew something', 'wave good-bye', 'write your name', etc., C scored I 2 out of I 3 correct. His one incorrect response was to 'move your eyes up', where he instead tilted his whole head back. However, on the Kimura movement copy test of non-representational gesture (Kimura I982), C scored extremely low, getting 7 points $(29 \%)$ with

[2] The task was repeated in this fashion as we have noticed on a number of occasions that $\mathrm{C}$ is markedly better at carrying out various tasks after a delay than immediately after he has been exposed to them. We propose to investigate this intriguing fact further in future research. 
his right hand and o with his left hand. In this test, the subject has to imitate meaningless sequences of gestures (which have no relationship to BSL signs). The subject sees three different movement sequences which are to be copied, all involving only one hand and arm. For example, the first sequence begins with an open hand with spread fingers. The arm is positioned across the body with the hand in front of the opposite shoulder. From this position the arm moves steadily across the front of the body to an outstretched position on the opposite side to the movement's beginning. As the arm moves across, the fingers move from the spread apart position to touching each other. Two points are scored if the movement is copied correctly on the first trial; one point if it is copied correctly on the second trial, and no points if it is incorrect on both trials. A score below $90 \%$ is considered apraxic. Full details of both these and other tests of apraxia are given in Morgan et al. (2002).

Apart from the dissociation between his 'verbal' and 'performance' abilities, $\mathrm{C}$ also shows striking dissociations within his linguistic talent. His acquisition of the morphology and lexicon of new (spoken) languages is typically extremely rapid and proficient, whereas his acquisition of syntactic structure appears to reach a plateau beyond which he is unable to proceed. This contrasts with normal second language learners, who characteristically have greater difficulty with the acquisition of morphology than of syntax.

The dissociations we have already documented suggest that BSL should provide an interesting test for C. First, will his linguistic prowess compensate for his visuo-motor deficits, or will these disabilities preclude his acquisition of BSL? Second, assuming that he displays some ability to learn BSL, will his mastery of the language show the same linguistic asymmetries as are seen in his spoken languages? Finally, will there be a contrast between his BSL production and his BSL comprehension?

The structure of the rest of the paper is as follows: in section 3, we spell out these hypotheses in more detail, in terms of the challenges that BSL presents $\mathrm{C}$ with; in section 4, we give an overview of the structure of BSL; in section 5, we give details of the procedures and results of our investigation, detailing the programme of BSL teaching used for C over some five stages; in section 6 , we discuss the most salient of these results; section 7 is a general conclusion.

\section{The Challenge for Christopher}

The most obvious difference between BSL and the other languages $\mathrm{C}$ has encountered is the modality in which it is produced. Signs are articulated through coordinated limb, torso, head and facial movements and, as communication is necessarily face to face, looking at the interlocutor while he or she is signing is the only means of access to linguistic information. In both production and perception, users of signed languages have to use configurations of movements and spatial information, and they have to be 
aware of their interlocutor's visual attention. As we shall see, basic perceptual and articulatory processes, as well as higher-order (morphological, syntactic, semantic and even paralinguistic) processes, are integrated in the performance of normal signers of BSL, in that all of them involve producing manual and non-manual movements, and interpreting those of the interlocutor, in order to convey and receive linguistic information (see Neidle et al. 2000 for a comparable description of American Sign Language). Accordingly, BSL provides $\mathrm{C}$ with a new challenge, as it combines several aspects of behaviour with which he has acute problems in the non-linguistic domain, but where these behaviours are recruited for linguistic and communicative functions.

A less obvious, but crucial, consideration is that learners of BSL (or any signed language) are faced with the fact that it has no written script, apart from the complex and limited notational systems used by researchers. Except for his native first language, English, all of C's previous languages have been acquired on the basis of an input which includes written material, using books, newspapers and grammars. Even in English, written texts now constitute a major part of the input to him, and it is clear that he is obsessed with the written word, sometimes to the exclusion of spoken language. We have tentatively experimented with teaching C 'Sutton Sign Writing' (Sutton I999), but this requires drawing abilities which are probably beyond him. It is clear that the lack of an easily accessible written system for BSL was a major hurdle for $\mathrm{C}$ to clear, before he could come properly to grips with the intricacies of the new grammar.

Against this background we made the following predictions. BSL combines properties which should make it simultaneously both congenial and uncongenial for him. On the one hand, it falls within the domain of C's

obsessional talent: it is a natural language with all the usual properties of natural languages. On the other hand, it exploits the visuo-spatial medium which causes $\mathrm{C}$ such difficulty in performing every-day tasks. We expected that his linguistic talent would outweigh the disadvantages of the medium, and that his ability in BSL would mirror his mixed abilities in spoken languages: that is, he would make extremely rapid initial progress; his mastery of the morphology and vocabulary would be excellent in comparison with BSL syntax; there would be some mismatch between his production and comprehension skills; and he would have significant difficulty with those syntactic properties (such as word order) that differentiate BSL from spoken English.

\section{AN OVERVIEW OF BSL}

It is important to stress that BSL is as expressively rich as any spoken language, and is unrelated to spoken English. As a natural human language, it has all the linguistic ingredients characteristic of any other language: a 
lexicon and a 'computational system' (Chomsky I995: 6, 22 I) with syntax, semantics, phonology and morphology (see e.g. Brennan I990, I992; SuttonSpence \& Woll I999). As in all other signed languages previously studied (e.g. Klima \& Bellugi 1979, Pizzuto et al. I990, Engberg-Pedersen 1995, Morgan I999, Neidle et al. 2000), the surface manifestation of BSL grammar is spatially organised, such that signers make structured use of space and movement.

In this section we describe relevant aspects of the linguistic structure of BSL. We first describe aspects of the BSL lexicon and then proceed to levels of signing beyond the single sign, describing the use of locations in sign space and sign modifications through morpho-syntactic devices. Throughout this description of morphological and syntactic processes, we also outline the role of non-manual features, in particular, facial expression (or facial-action). This description will form a necessary back-drop to an account of the rather piecemeal acquisition of these different parts of BSL by C.

\section{I The BSL lexicon}

This description of sign phonology is necessarily brief and specifies only details which are relevant to C's learning of BSL. In all signed languages, signs are formed through rule-governed phonological processes. For the purposes of this paper, we describe the use of sign space for the articulation of single signs with a conventional five parameter model of sign formation. Stokoe (1960) first proposed three aspects for a sign: hand-shape, location and movement. Later revisions of his model added the parameters of orientation of the palms relative to the body, and facial-actions (see e.g. Brennan I990).

All signs in BSL are made up of a hand-shape in combination with the other sign parameters, i.e. different movements at different locations in different orientations to the body, and potentially accompanied by different facial expressions (see the pictures of hand-shapes in diagram I). Signs can

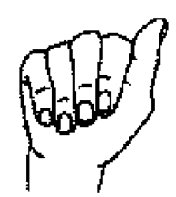

A

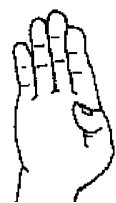

B

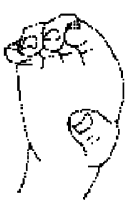

$\mathrm{C}$

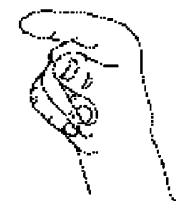

$\mathrm{G}$

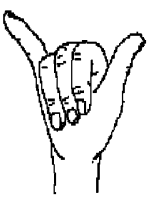

$\mathrm{Y}$

Diagram I

Sample BSL handshapes 


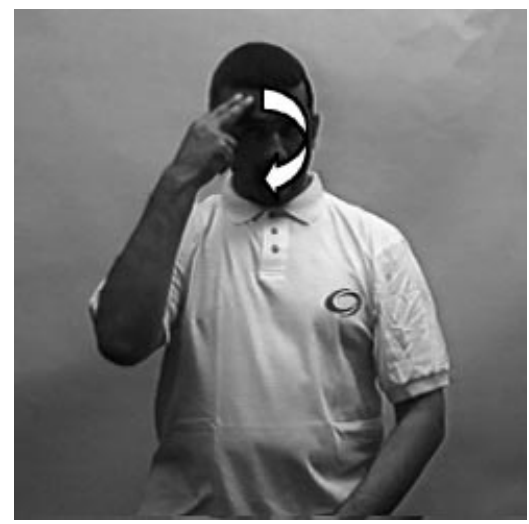

Figure I

NAME

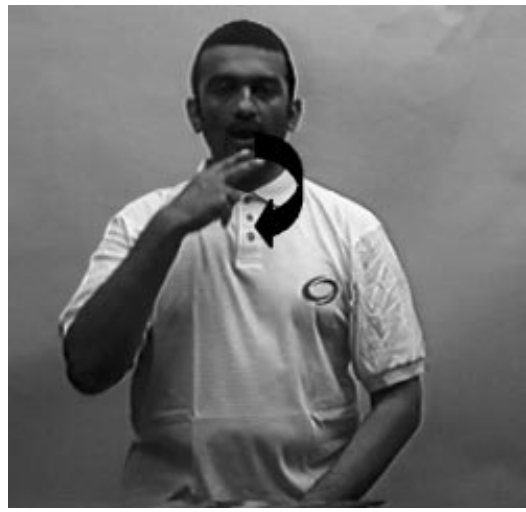

Figure 2

AFTERNOON

share one or more parameters. For example, the signs NAME (figure I) and AFTERNOON (figure 2) have identical hand-shape $(\mathrm{H})$, movement (twist at the wrist), orientation (palm faces down) and facial expression (neutral), but differ in location (forehead and chin, respectively).

For each parameter there is a limited set of available features. For example, all signs are confined to a limited space in the area of the upper body, and not all possible formations of the hand can appear. Signs may be classified according to their form, as one or two-handed. Two-handed signs can have symmetrical movement, or one hand (the dominant one) can move 
while the other serves as a location. Signs also differ in contact with the signer's body, and whether the hands touch each other (for a detailed discussion see Sutton-Spence \& Woll I999; or for ASL, Liddell \& Johnson I989). Four hand-shapes, 'B', ' 5 ', 'G' and 'A', are found in $50 \%$ of all BSL signs (Sutton-Spence \& Woll I999: I62) and have been termed unmarked. Two further constraints, which appear to be universal, have been proposed for two-handed signs (Battison I978). The Dominance constraint states that if a two-handed sign has different hand-shapes, the non-dominant hand may have only a limited number of hand-shapes and forms the location for the whole sign. The Symmetry constraint states that if both hands move independently, both must have the same location, hand-shape and movement (either simultaneous or alternating), and the hands' orientation must also be symmetrical. In this case, there is no dominant hand.

\subsection{Morpho-syntax}

BSL has a complex system of morphological and syntactic processes. We describe those of most relevance to the learning of BSL by C: the marking of negation, verb agreement and questions.

\subsection{Negation}

There are three main markers of negation in BSL: facial-action, head movement and manual negation signs, or signs with negation incorporated in them. Each marker can occur in conjunction with the others, and facialaction can vary in intensity. Signs are often negated through specific mouth movements which accompany negation signs. Head movements (in particular a head-shake or a slight head turn to the side) may be single or repeated. The head-shake (hs) can vary in the extent to which it is spread across a sentence, as indicated by the horizontal line in (3) and (4). The horizontal line before the ' $\mathrm{t}$ ' indicates the topic $(\mathrm{t})$.

(3)

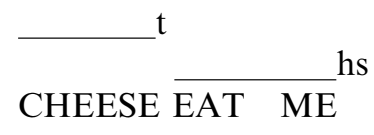

'I don't eat cheese. '3

[3] The capitals indicate individual signs; the elements t (topic), hs (head-shake), hn (headnod), etc. indicate supra-segmental aspects of the signed sentence, with their scope marked by the horizontal line. 
(4) hs

CHEESE EAT ME

'It's not the case that I eat cheese.'

This difference functions to negate different parts of the phrase: that is, to mark the scope of negation.

There are also many signs which include negation in BSL, such as NOTHING, NOT-YET, WILL-NOT, WHY-NOT and SHOULD-NOT. These signs may be accompanied by facial-action and head movements, and usually appear at the end of the sentence. Finally some signs, usually those representing verbs of experience or sensation, have their own negation form, such as KNOW-NOT, LIKE-NOT, WANT-NOT and BELIEVE-NOT. The interpretation of these forms is always such that the negative has scope over the predicate, as in ' $\sim$ [know]' rather than ' $[\mathrm{know}] \sim$ '. Morphologically, the negation element (NOT) of these forms is transparent, but the affixation of negation to the lexemes KNOW, BELIEVE, etc. gives rise in some instances to morphophonemic changes in their form, which renders them opaque. Thus, BELIEVE and LIKE remain unchanged by the addition of negation, but KNOW and WANT undergo some change. The situation is comparable to the affixation of the plural morpheme in spoken English, where the plural marker is itself systematically transparent, but where the stem to which it is affixed may change, as in the contrast between cuff $\mid$ cuffs and leaf |leaves. Signed sentences, then, often contain multiple negation markers, as shown in (5), where 'IX' indicates an indexical point to sign space.

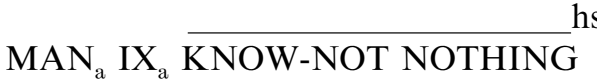

'I really don't know the man.'

In such cases, the presence of a negation-sign (i.e. NOTHING) is optional, its effect being mainly to add emphasis to the negative meaning of the sentence. The representation 'NOTHING' disguises the fact that the sign can be used either for an argument (as in 'he ate nothing') or, as here, as a simple negator.

\subsubsection{Verb agreement}

One class of verbs in BSL, so-called 'agreement verbs', can be modified to show manner and aspect, and the person, number and class of the subject and direct object. As an example, nominals introduced for the first time into discourse may be accompanied by a point to a location in sign space, and verb signs move between such points to specify the verb's subject and object. Subsequent re-pointing to a previously established location in sign space functions as a pronominal reference (marked as 'PRON') to the earlier articulated nominal, as illustrated in (6). 
G. MORGAN, N. SMITH, I. TSIMPLI \& B. WOLL

(6) MAN IX MROTHER IX $_{\mathrm{b}}{ }_{\mathrm{a}}$ TELEPHONE $_{\mathrm{b}}$ PRON $_{\mathrm{b}}$ NOT-HAVE WORK

'The man telephoned his brother, but he wasn't there, he was working.'

The use of agreement verbs may also be used in conjunction with referents present in the context. Where such referents are present, they are used as the syntactic location of the subject or object: e.g. I-ASK-YOU or YOU-TELLHER, where the sign begins at the signer and moves in the direction of the 2nd person, or from the 2 nd person towards the location of the 3 rd person standing at another location. Signers repeating a sentence involving a directional affix on a verb modify that verb to show their own location rather than that of the original signer. Thus I-TELEPHONE-YOU (where the sign moves from location A to location B) should be repeated by another signer with the sign moving from location B to location A. As we shall see below, this caused $\mathrm{C}$ some difficulty. From this brief description it is clearly important for the learner to develop an initial tacit understanding of sign space.

\subsubsection{Questions}

Questions in BSL have one or more of three features: a question sign, a characteristic facial-action and a characteristic sign order.

The two question forms in BSL we describe here are Wh- and Yes-No questions. Wh- questions are formed with a question sign such as WHAT, WHO, WHERE, WHY or HOW. Question signs most often come at the end of the sentence, but sometimes the Wh- sign appears both at the beginning and at the end of the questioned clause as, for example in WHERE CAT WHERE ('Where is the cat?'). Facial-action is also important: with Whquestions, the brows are generally furrowed, the eyes are slightly closed, and the head is thrust slightly forward or tilted to one side: the symbol 'bf' is used to refer to this combination of actions. Yes-No questions are also signalled by facial-action: usually raised eyebrows, opened eyes and a slight backwards thrust of the head and shoulders: the symbol 'br' is used to refer to this combination of actions. The precise extent of this supra-segmental articulation determines the scope of the interrogation in the question. There is no special Yes-No question manual sign at the beginning or end of the interrogative. The two uses of the brow in Wh- and Yes-No questions are shown in (7).

(7)
(a) BOOK WHERE 'Where's the book?'

(b)

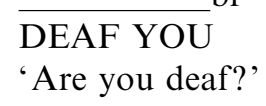

With this background we can now turn to the core of the present study: the attempt to teach BSL to Christopher. 


\section{LEARNING BSL}

\section{I Input}

A qualified deaf BSL tutor taught $\mathrm{C}$ a conventional (CACDP stage I) ${ }^{4}$ BSL class once a month, concentrating on the core grammatical properties of the language (see the appendix for the schedule of classes). Over I 2 months, there were accordingly I 2 hours of formal teaching, which was supplemented by conversation with a native (deaf) signer, who went over the same material in a less formal context between classes. The total amount of BSL contact was therefore about 24 hours. Although the curriculum was divided into formal lessons and informal discussions, the teaching was sufficiently flexible that both types of session contained both types of material. By way of comparison, this is more than twice as much as C's exposure to each of Berber and Epun, ${ }^{5}$ the other (spoken) languages we had taught him previously (see Smith et al. I993, Smith \& Tsimpli I995). In teaching $C$ these new languages we had left him with tape-recorded and written versions of the material he had been exposed to, but with no further texts or documentation in these languages. ${ }^{6}$ In teaching him BSL we could not leave him any written material, but we did provide him with a BSL dictionary and some video material. He used these sporadically, but he never mastered the transcription used in the dictionary, and soon broke the video machine. In fact his use of any of the material for spoken or signed languages appears to have been minimal.

As a form of control, we taught the same curriculum to a group of 40 (30 female, Io male) hearing, talented second-language learners, aged between I 8 and 30 years, who all spoke English as a first language. They were students who had progressed to post A-level ${ }^{7}$ in either French, German or Spanish, but who were not native learners of these languages. They had a one-hour class once a week for I 2 weeks, and so were exposed to comparable BSL input, albeit over a shorter time-span. Although we attempted to make the input to $\mathrm{C}$ and to the comparator group as similar as was feasible, we deliberately adapted the curriculum to the learners' profiles. Neither $\mathrm{C}$ nor his tutor could cope with more input than he received: he got tired and distracted easily, and he quickly got bored during his BSL class, as he was unable to have recourse to talking in different languages as was his custom in our spoken interactions with him.

[4] Council for the Advancement of Communication with Deaf People, Stage I (Basic) Certificate in BSL. The curriculum is available from CACDP, Durham University, Science Park, Block 4, Stockton Road, Durham DHI 3 UZ, UK.

[5] Note that Epun is an invented language; it has nothing in common with Nupe, a BenueCongo language, specifically, part of the former Kwa group.

[6] There are no other documents in Epun, and C's mastery of the Arabic script in which Berber is usually written is inadequate to let him read primary material in this language.

[7] This marks a level of attainment sufficient for starting a University degree in the literature of that language in the UK. 


\section{G. MORGAN, N. SMITH, I. TSIMPLI \& B. WOLL}

All classes and discussions were filmed on video-tape. Coding and transcription followed conventional sign language research protocols (see Brennan 1990, 1992; Sutton-Spence \& Woll 1999). All transcriptions were checked with a second native signer, and reliability was established at above $90 \%$. All of C's spontaneous signing which showed any use of negation, questions or agreement was transcribed (details are given in table I below, p. I7). We took a random ten-minute sample from each hour of exposure for closer scrutiny, recording his use of sign to communicate, and cataloguing the development of his looking behaviour and his improving mastery of sign phonology.

\section{I.I Methods of teaching, assessment and transcription}

The 24 hours of BSL exposure were divided for the purposes of analysis into five stages: four periods of 5 hours, and a final period of 4 hours. At each stage we assessed C's progress before increasing the complexity of the material he was exposed to. The formal classes exposed $\mathrm{C}$ to the grammatical structures of negation, verb agreement, questions, and sign-order, as well as aspectual morphology, classifier constructions, non-manual modifiers and spatial location setting. Throughout the teaching programme we focused on the three aspects of C's acquisition of BSL, listed in (8).

(8) (a) His articulation and comprehension of lexical signs.

(b) His articulation and comprehension of grammatical devices.

(c) His mastery of paralinguistic devices and non-verbal communication.

During the 5 periods of exposure we assessed C's uptake of BSL in each of these domains, using translation tasks from BSL to English and from English to BSL, as well as analysing his spontaneous and elicited use of sign in conversation. In addition, we carried out a variety of tests of C's general cognitive abilities. To anticipate the discussion below, $\mathrm{C}$ has acquired PARTIAL knowledge of BSL and some ability to put that knowledge to use. We will attempt to explain this partiality by relating it to aspects of his skewed psycholinguistic profile.

\subsection{Results of C's learning of BSL}

In this section we present a broad overview of C's production and comprehension of BSL across each of the 5 stages. We describe his development on the basis of observational and experimental data in the three areas listed in (8) above. At the beginning of the project, $\mathrm{C}$ had reported that he knew some signing, but when questioned further, this turned out to be letters of the manual alphabet, which he claimed to have learnt from deaf people. 
On his first exposure to BSL proper, $\mathrm{C}$ already manifested a number of behaviours in his production and reception of sign which mark him out as an atypical learner. The most striking of these were his echopraxia (repeating of signs without understanding them $)^{8}$ and avoidance of direct eye-contact with the signers around him. Initially $\mathrm{C}$ avoided gazing at his tutor's eyes, contenting himself with rapid glances at her face. For instance, in a narrative story-telling task, $\mathrm{C}$ took one glance at the addressee at the beginning and then averted his eye-gaze for the 30 seconds of the story, with the result that he had great difficulty in understanding what was being reported, especially the roles of and switches between characters. By contrast, after the same amount of exposure, the members of the comparator group ALL looked at the addressee's face throughout the narrative. They too had periodic problems of comprehension, but these were easily accommodated, as the signer could infer their lack of understanding from their expressions. A further indication of his atypicality is that, if something else attracted his attention, $\mathrm{C}$ would often look away when the interlocutor was in mid-sentence. When he did pay attention, he appeared to fixate on one topic, and attempts by the interlocutor to open up the conversation to more general topics were met by $\mathrm{C}$ insisting on bringing it back to this earlier topic. This may be a further manifestation of the obsession associated with his mild autism, and it is also something that we have observed with other people with learning difficulties.

In the first hours of exposure to BSL an interesting paradox appeared. Despite his apraxia and his resultant problems in forming and moving signs in sign space, $\mathrm{C}$ was very keen to gesture, and spontaneously offered arbitrary gestures for novel objects and concepts. In the initial assessment of his comprehension of single signs, based on choosing one of four pictures immediately after seeing the sign, he responded with abnormally quick guesses. $\mathrm{C}$ often seems to believe that, in spoken language as in signed language, his linguistic abilities are better than they really are: for him, these wild guesses may well not be distinct from informed responses. However, his spontaneous attempt to mime or gesture is surprising, as it contrasts markedly with the usual absence of gestural behaviour when he is speaking. Nonetheless, most of these gestures appeared to be meaningless combinations of limb movements. When he began to replace random gestures by real signs, his signing was generally limited to utterances made up of single signs or two-sign combinations.

\subsection{Lexical development}

Several tests of vocabulary acquisition, dealing with both the comprehension and the production of signs, were carried out at each stage. At the end of each

[8] Several examples can be seen in the extended dialogue transcribed in (27) below. It is worth noting that $\mathrm{C}$ not only uses echoes, but also introduces new topics. 
period, we selected two groups of between 30 and 40 signs which he had seen in his classes as well as produced himself. For the measurement of sign comprehension he had to match signs to representative pictures: his tutor signed each vocabulary item and $\mathrm{C}$ had to point to the matching picture from a choice of four. We allowed two attempts at identifying the signs as $\mathrm{C}$ often looked away before he had seen a sign. With a different list of signs we then measured the accuracy of his sign production and memory for signs: the tutor showed $\mathrm{C}$ a picture and asked for the corresponding sign. We checked his tutor's scoring by asking an independent native signer to repeat C's signs to show that they were recognisable out of context. In each period, we focussed on new vocabulary items that $\mathrm{C}$ had been exposed to, so the vocabulary was different across the various periods of testing. Test scores for single sign comprehension and production are presented in figure 3. As can

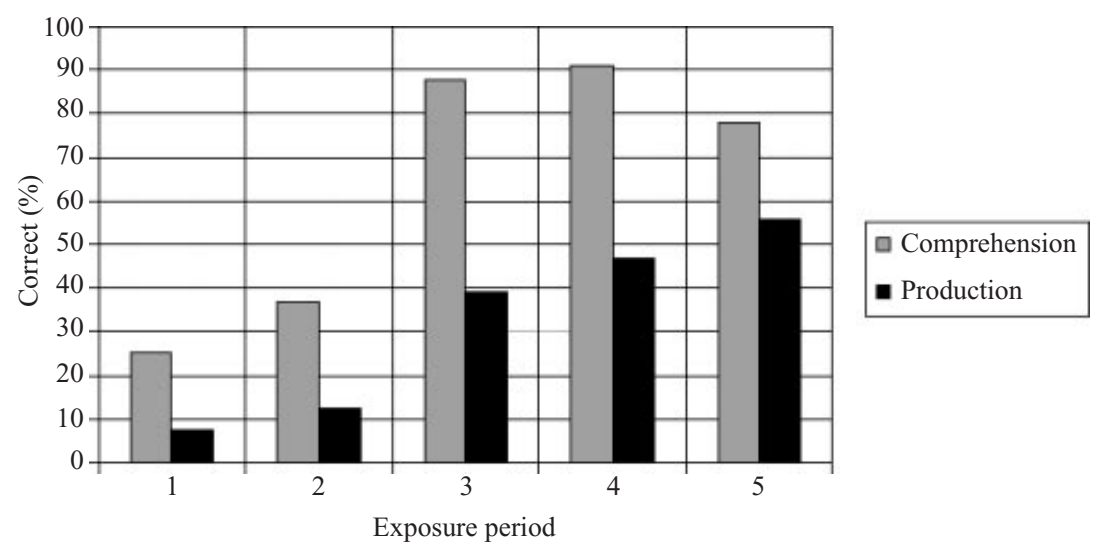

Figure 3

Tests of lexical signs

be seen, $\mathrm{C}$ made significant progress in his comprehension and production of signs throughout the investigation.

As mentioned above, in the initial test of his comprehension of single signs, he made abnormally quick responses but, although he was very quick in coming to a decision, he scored at chance level (I $2 / 48=25 \%$ ) compared with scores of between $54 \%$ and $75 \%$ correct on the same items by the comparator group.

After this inauspicious beginning, the results shown in figure 3 reveal that, in the comprehension of single signs and short sentences, $\mathrm{C}$ made steady progress, scoring within normal limits for sign learners as represented by the comparator group. Moreover, from period 3 onwards we observed the gradual appearance of some strategy to his learning. As more complex signing was introduced, $\mathrm{C}$ showed some success in analysing the grammatical 
features, even though he was rather limited in comprehension and seriously limited in his production of these complex forms compared with the comparator group.

In his first hours of exposure to BSL, C was keen to gesture, spontaneously offering arbitrary gestures for novel objects and concepts. Despite this enthusiasm, he only produced 3 out of 40 signs $(7.5 \%)$ correctly in the first test. One of the differences in C's use of BSL in this period, compared with that of other learners, was that he appeared (both in comprehension and production) to focus on isolated aspects of a sign's formational parameters, assigning meaning based on some similarity to another sign, rather than processing all the features as a whole. Often one parameter was produced incorrectly, although in a subsequent attempt at producing the same sign this parameter might be correctly used, while another parameter previously selected correctly was incorrectly articulated. For example, the sign DOG in BSL is signed with both hands making small up and down movements in front of the signer at waist level. The hand-shape used is an $\mathrm{H}$ hand (only the index and middle fingers are extended and they are touching each other). On one occasion $\mathrm{C}$ signed DOG with his arms outstretched at his side but with correct movement. On another occasion when he signed DOG again he used the correct location, but moved his hands in circles rather than up and down. Another example was observed with the sign SISTER, articulated with a bent index finger moving up and down on the bridge of the nose. $\mathrm{C}$ used a flat hand-shape in the right location, but in subsequent conversation moved the location to his cheek and produced the right hand-shape.

In general, much of his core productive vocabulary was made up of signs he was able to produce easily despite his coordination problems; for example, signs such as BOOK, SIGN, DRIVE, WORK and LIKE (figure 4). His ability to produce recognisable signs increased steadily, and by period 5 , $\mathrm{C}$ was producing over half $(56 \%)$ of the signs in vocabulary tests correctly, where a sign was credited as being articulated correctly if a native signer could recognise it out of context.

As is usual in language acquisition, C's ability to produce stretches of signed utterances lagged systematically behind his ability to decode such sequences. This was particularly clear in his attempts at translating more complex sentences. As we tested his comprehension of such sentences, $\mathrm{C}$ was more successful at translating them into (written) English than at producing them in BSL. Overall, his comprehension demonstrated knowledge of many more sign meanings than was evident from his production. In C's development of the BSL lexicon his production of signs was significantly hampered by his apraxia, even though in some domains his comprehension was within normal levels for sign learners of his experience. As a final observation, he manifested a consistent strategy across the learning period of focusing on isolated signs and parts of signs, rather than processing a sign sequence holistically. 
G. MORGAN, N. SMITH, I. TSIMPLI \& B. WOLL



BOOK

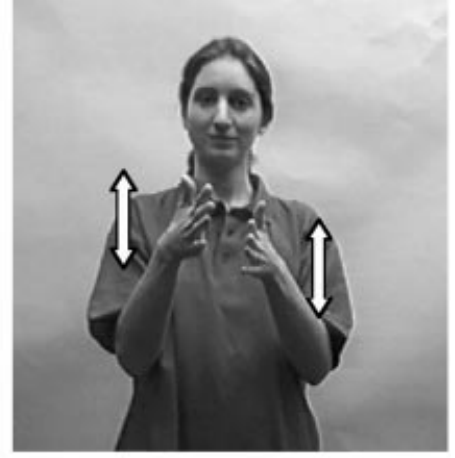

SIGN



DRIVE

Figure 4

Example signs that $\mathrm{C}$ was able to produce easily

\subsubsection{Morpho-syntax}

We next chart C's gradual mastery of the core grammatical features of BSL. We concentrate on three aspects of the grammar: negation, verb agreement and questions (both Wh- and Yes-No). In general, C developed increased productive and receptive knowledge of these three aspects of BSL throughout the five stages.

\subsubsection{Negation}

As documented in section 4 above, BSL expresses negation in three ways: internal to the sign (incorporation), e.g. KNOW-NOT, HAVE-NOT; through a supra-segmental negation marker (head-shake); and by means of 
a separate manual negation sign, e.g. NOTHING. Combinations of the three are also possible. Across the five periods of learning, $\mathrm{C}$ used all these three negation devices in his spontaneous signing. The overall incidence of each is presented in table I. The total number (n) of tokens of grammatical utterances is shown next to the relevant stage in the top line. We have excluded from this table the large number of C's uses of the head-shake alone, including only its use in conjunction with other manifestations of negation. We have also marked ungrammatical uses of negation separately.

\begin{tabular}{llllll}
\hline Time period & $\begin{array}{l}\mathrm{PI}_{1} \\
{[\mathrm{n}=\mathrm{I} 2]}\end{array}$ & $\begin{array}{l}\mathrm{P}_{2} \\
{[\mathrm{n}=29]}\end{array}$ & $\begin{array}{l}\mathrm{P}_{3} \\
{[\mathrm{n}=6]}\end{array}$ & $\begin{array}{l}\mathrm{P} 4 \\
{[\mathrm{n}=\mathrm{I} 9]}\end{array}$ & $\begin{array}{l}\mathrm{P}_{5} \\
{[\mathrm{n}=7]}\end{array}$ \\
\hline Incorporation & 4 & $\mathrm{I}$ & & & \\
Negation Sign & 5 & 2 & & 8 & \\
Head-shake across sign & 2 & $\mathrm{I} 4$ & 4 & $\mathrm{I}$ I & 5 \\
Final Head-shake & $\mathrm{I}$ & 2 & 2 & & 2 \\
Ungrammatical & $\mathrm{I}(8.3)$ & $8(27.6)$ & $3(50)$ & I (5.3) & $2(28.6)$ \\
$\quad$ utterances (\%) & & & & & \\
\hline
\end{tabular}

Table I

Christopher's use of different types of BSL negation and ungrammaticality

In period I, C used a combination of negation devices, as illustrated in (9). He used the manual negation signs NO and NOT-YET, as well as producing some verbs with (incorporated) negation internal to the sign, e.g. KNOWNOT, WANT-NOT, AGREE-NOT. He used this device ungrammatically as well, over-generalising incorporated negation to verbs which disallow it in BSL, as in example (9a); and in one session (after 3 hours of exposure), he produced an ungrammatical as well as a grammatical use of negation for the same verb.

(9) (a) *ME WATCH-NOT

'I don't watch TV.'

(b)



Although the use of the head-shake in (9b) is grammatical, it is unusual for it to follow the verb rather than be produced together with it. Throughout the first period, $\mathrm{C}$ tended to separate the sign and the negation, producing 
head-shake final sentences as well as head-shakes without signs. On occasion, however, he was able to combine the head-shake with other signs, as in (Io).

(Iо) (a)

a) hs

CHEESE EAT ME

'I don't eat cheese.'

(This is an alternative, contrastive, version of the form shown in (3).)

(b)

$$
\begin{aligned}
& \text { ME SIGN } \\
& \text { 'I don't sign.' }
\end{aligned}
$$

This use of head-shakes may appear relatively simple, but it is impressive when considered in comparison with his general communication in spoken language, where he does not use such gestures, but instead uses verbal negation without movement of the head or hands. In fact, on the adapted BDAE mentioned in section 2 above (Goodglass \& Kaplan I972), C had difficulty in moving his head correctly on the bucco-facial part of the test. To show sneezing, he moved his hand to his face; to show a kiss, he kissed his own hand; and he could not move his eyes up without simultaneously moving the whole head.

During period 2, there was rapid development of C's use of negation markers, and he produced 29 negated sentences. He used appropriately verbs with incorporated negation, including HAVE-NOT and CAN-NOT, but at the same time he continued to over-generalise this strategy to verbs which cannot incorporate negation, e.g. *DRINK-NOT, *WATCH-NOT and *EAT-NOT. Further, his previous correct use of the supra-segmental headshake marker was typically replaced by a preference for using a head-shake between the verb and the subject, as in (II).

(I I) (a) BEER (DRINK) hs ME 'I don't (drink) beer'

(b) FRENCH SPEAK hs HE 'He doesn't speak French.'

Although not fully acceptable, C's production of such sentences indicates that, at the relevant stage of his BSL development, he was attributing morphological status to the head-shake marker of negation. This replacement of the supra-segmental head-shake by the purely morphological is consistent with his general difficulty in perceiving and producing supra-segmental features both in spoken languages and in BSL. Typically, C does not pick up on the facial-actions that accompany signs: for instance, he did well on the comprehension of negation elements, but less well on the comprehension of manner adverbials, such as SLOWLY, produced on the face accompanying the signs. 
The same ungrammatical pattern was also found in structures with verbs which require incorporated negation. There were five examples of this overgeneralisation error, including those in (I2).

(I2) (a)

(a) hs

*WANT ME

'I don't want.'

(b) hs

*BELIEVE ME

'I don't believe.'

C's use of the head-shake with different types of verbs provides further evidence for the claim that the head-shake has morphological status in his sign language. Thus, in period 2, $\mathrm{C}$ uses both incorporated negation (a bound morpheme) and the head-shake (a free morpheme) to encode negation. That mastering negation caused him some problems - presumably a reflection of the inherent complexity of negative sentences - is shown by the fact that there were several examples where he dropped verbs or other signs in his production of negative sentences, as in (I Ia) and (I3), where he omitted the parenthesised DRINK.

hs

\section{BEER (DRINK) ME}

'I don't (drink) beer.'

The first two examples showing combined negation markers appeared after 6-8 hours of sign exposure, when $\mathrm{C}$ combined head-shakes with the negation signs NO and NOTHING. The first use, shown in (I 4a), where the form ' $N O$ ' is the same as the sign used in Yes-No questions, was the most complex negation produced up to this point; the correct target is given in (I4b).

(I4) (a)

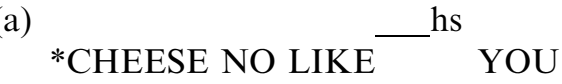

'You don't like cheese.'

(b)

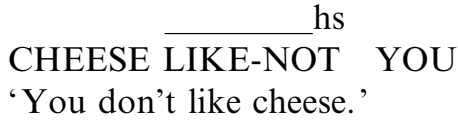

$\mathrm{C}$ does not incorporate negation within the verb (LIKE-NOT), and he produces the head-shake between the verb and the pronoun rather than simultaneously with the verb, as with the V NEG (Subject) pattern in (I I). In the target sentence (I $4 \mathrm{~b}$ ), the simultaneous production of the negated verb 


\section{G. MORGAN, N. SMITH, I. TSIMPLI \& B. WOLL}

with the head-shake requires an analysis of the head-shake not as a morphological but as a suprasegmental marker of negation; something which is probably not part of C's BSL grammar at this stage.

In period 3 (IO-I 5 hours of sign exposure), C's signing was generally reduced, and he used fewer negation markers than in any other stage. $\mathrm{He}$ used only head-shake markers, with one example combining two negation markers: a head-shake both before and after the verb: *hs LIKE hs. Throughout this period, he continued to use citation forms of verbs with head-shake, rather than modifying the sign to incorporate negation. We tested both $\mathrm{C}$ and the comparator group on video-taped signed utterances with and without negative elements, where the task was to pick the appropriate picture, e.g. 'the dog without the bone' from a set of four. The tests involved comprehension of negation markers: either incorporated, lexically expressed, or indicated through head-shakes. C scored within normal limits, identifying I3 of I4 negation markers (93\%; chance was $50 \%$ ), compared to scores of between $86 \%$ and $100 \%$ by the comparator group (SD $4.8 \%$ ). We also constructed a grammaticality judgement task involving signed sentences with incorporated negation on the verb, with half of the sentences ungrammatical combinations of negative marker and manual sign. C scored 6 out of Io correct (chance again was $50 \%$ ), compared with scores of $30 \%$ to $80 \%$ by the comparator group (SD I $5.3 \%$ ), perhaps indicating that the test is too undiscriminating to be useful.

Although in this period his production of negatives is reduced, C's performance on tests of comprehension is comparable to that of other learners. Moreover, although his production still includes ungrammatical uses of negation markers, his grammaticality judgements - where he had to decide whether a negated sentence was signed appropriately or not - suggest that his BSL development is within the range of the comparator group.

In period 4 (after I5-20 hours of exposure), C produced I9 negated utterances, I I of which were marked appropriately by means of a head-shake simultaneous with the manual sign. Thus, although $\mathrm{C}$ exhibited wider knowledge of BSL negation markers, he frequently used just a head-shake, while relying on the conversational context to make himself understood. This over-riding use of the head-shake in his spontaneous productive signing continued until the end of our observation. However, he also experimented with the positioning of the head-shake in its combination with other signs. We observed variation in his use of this marker before the sign, e.g. hs ME LIKE 'I don't like'; between the verb and the object, e.g. RUGBY (LIKE) hs YOU 'You don't (like) rugby', and correctly articulated over the signs as in (I5).

HAT NOTHING

'There's no hat.' 
Although the number of tokens of negation markers produced in this period is relatively small, it is clear that the head-shake has been grammaticalised as the marker of negation in C's BSL. Evidence for the morphological, rather than supra-segmental, status of the head-shake is still found, although there appears to be some variation in its order with regard to the verb. However, it is in this fourth period that the use of the head-shake as a supra-segmental feature begins to be found. As this pattern is also attested in period 5, we may tentatively conclude that the negatives from periods 4 and 5 mark a transition from the morphological to the target status of the head-shake in C's BSL. An alternative possibility is that the headshake has a dual status in C's grammar at this stage, being optionally either a morphological marker or a supra-segmental feature. Although odd in spoken languages, this dual status seems to be related to the gestural nature of the head-shake in his developing BSL grammar.

In period 5, five of his seven negations were expressed through a headshake across the sign, but he continued to make errors in using head-shakes where a verb should have been modified by incorporated negation. Two examples of this from his spontaneous signing are shown in (I6).

$$
\begin{aligned}
& \text { (a) hs } \\
& \text { *WANT } \\
& \text { 'I don't want' } \\
& \text { (b) hs } \\
& \text { *LIKE } \\
& \text { 'I don't like' }
\end{aligned}
$$

Here, $\mathrm{C}$ appears to have adopted the strategy of using just a head-shake without negative incorporation. As with other aspects of his signing (e.g. questions), this reduced production relied on context for its successful interpretation.

We pursued the question of whether $\mathrm{C}$ was really more competent with negation than was observable in his spontaneous signing. As he had begun to rely on head-shakes alone in the final stages of his BSL exposure, we tested his ability to repeat some 30 negated sentences more complex than those he had previously produced himself. His sign tutor (A) signed the sentence, and $\mathrm{C}$ had to repeat the sentence 'sign-for-sign' including all the non-manual elements. The same patterns observed in his spontaneous signing appeared across the 30 negated sentences. He often delayed the negating head-shake to the end of his signed sentence as in (I7).

A: CINEMA ME CAN-NOT GO

'I can't go to the cinema.' 
G. MORGAN, N. SMITH, I. TSIMPLI \& B. WOLL

\section{C: CINEMA ME CAN-NOT GO hs}

'I can't go to the cinema.'

In several sentences, he dropped parts of the original target in his repetitions as in the examples in (I8).
A: HOME-WORK TEACHER HELP-ME
'The teacher didn't help me with my homework.'
C: ME TEACHER hs
'The teacher didn't (help with my homework) me.'

hs

In all these examples, the verb 'help' is inflected for subject and object agreement by A, but not by $\mathrm{C}$, as shown explicitly in (I8b).

(b)

A: CAR FATHER ${ }_{a}{ }_{a} H_{E L P}-M_{b}$ ME $_{b}$ hs

'My father didn't help me with my car.'

C: CAR FATHER ME hs

'My father didn't (help with) my car.'

When his tutor attempted overtly to correct his omissions, C persisted in producing the reduced sentence, as shown in (I8c).

(c)
A: HELP-ME
'Didn't help me.'
C: CAR FATHER ME hs
'My father didn't (help with) my car.'

In more complex sentences involving negation, $\mathrm{C}$ was less able to process the sign semantically, or retain the correct negation scope. However, the fact that he failed to use the head-shake as a supra-segmental feature even in the imitation task indicates that its status for him is different from its status in the target language. In other words, C's inability to produce the head-shake as a supra-segmental feature (for reasons that may have to do with his autism and apraxia) forces an analysis of the head-shake in C's BSL as a morphological marker of negation, equivalent to 'not' or the anaphoric negator ' no'. The latter is characteristic of cases where the head-shake is used on its own, without any accompanying manual signs. Assuming that the head-shake across signs is indeed an affixal negative, rather than a scope marker, we suspect that $\mathrm{C}$ has over-generalised one form of affixal (morphological) negation, instead of distinguishing between the head-shake and incorporated negation. This gives rise to a more consistent grammar in 
his mind, in that KNOW-NOT type verbs, with incorporated negation, are subject to a lexical rule rather than a general morphological rule. Thus $\mathrm{C}$ has identified incorporated negation as a lexical marker of negation rather than as a morphologically productive process. The overgeneralisation examples with incorporated negation on verbs which disallow it in BSL are restricted and include verbs which occasionally appear negated with a head-shake (e.g. WATCH). The lexical analysis of incorporated negation is in fact supported by the input where some, but not all, BSL verbs have a negative form of this type. We assume that it is precisely on the basis of the inconsistent input that $\mathrm{C}$ has attributed lexical status to the incorporated negated verbs, treating such verbs as comparable to 'refuse' and 'deny', which, in spoken English, have an inherently negative meaning. If it is the case that target BSL includes incorporated negation as a morphological process, the implication is that $\mathrm{C}$ has not as yet figured out the semantic class of verbs which are negated in this way.

We further tested C's reduced ability to process more complex negative sentences in a series of translation tests. First, we tested his ability to translate BSL sentences into written English, and compared his BSL-to-English translations with translations into English from some of his other second languages, specifically Greek and Spanish. Although C's understanding and production of negation markers in BSL was comparable to that of other adult learners, he had more problems where sentences involved the manipulation of other components of BSL grammar (such as agreement in (Igb)) as well as negation. Selected translations illustrating his performance are provided in (I9).

(I9) (a) t hs

A: PLAY-PIANO SISTER KNOW-HOW

'As for playing the piano, my sister doesn't know how to.'

C: Sister did not play any piano.

(b) $\mathrm{t}$

\section{A: MY BIRTHDAY HUSBAND IX COOK NO} hs

'As for my birthday, my husband didn't cook anything.'

C: Her husband hates his birthdays.

(c) $\mathrm{t}$
A: NEW PUB m-a-r-y $\overline{\text { GO NO }}$
'Mary didn't go to the new pub'
C: Mary hates a pub.

hs

These examples show that C's translations were unlike those he produced from written input in other languages he is familiar with (see Smith \& Tsimpli 
I995: I $56 \mathrm{ff}$.$) . In particular, his translations from BSL to English are not$ word-for-sign nor 'literal' in any sense. Thus, it is interesting that although he failed to translate the negative sign in $(19 b, c)$, his choice of the verb 'hate', with its inherently negative meaning, suggests that he may have perceived the negation sign in the original BSL sentence, but has misidentified the sign for the verbs COOK and GO, respectively. This is further evidence suggesting that in his BSL C assigns lexical status to the incorporated negation. The mistakes he produced in translating COOK and GO are purely lexical (vocabulary) problems.

In these translation tasks, there were generally two factors which affected C's processing of BSL negation. First, he often mis-analysed signs, either because of their phonological similarity to other signs, or because he based his translation on a 'literal' visual representation of the sign. For example, he mistook the sign BEST for the sign GREEK (same location), WAIT for DOG (similar movement) and the verb FISH for the verb COOK (similar hand-shape).

This meant that although he was able to identify negation markers, his general problem with processing longer stretches of sign compromised his ability to translate negated elements correctly. In trying to process the meaning of other elements, his ability with negation was affected. An example of translation involving the sign CAN, which he had used several times and which was clearly part of his productive vocabulary, will serve to illustrate this 'conflict of interest'. In a sentence including this sign AND a negation marker, $\mathrm{C}$ translated $\mathrm{CAN}$ as 'nose', making a visual error caused by the fact that the articulation of the sign for CAN involves contact with the nose.

Second, $\mathrm{C}$ had a problem in retaining signs from the beginning of the sentence in his short-term memory long enough to let him see the whole sentence, process it and then translate it. It was apparent that the first signs produced were often omitted in the translations, with BSL proving more of a burden on his memory than comparable examples from Greek and Spanish presented in written form. That is, having to deal with complex signed sentences had a deleterious effect on his ability to process and retain negation. It would then seem that C's impaired performance on the translation task is due in part to a processing overload. A perennial problem with the BSL input is that it is not written, imposing time restrictions on its perception and analysis. This overload may also contribute to the misperceptions due to phonological similarity between the presented sign and other signs known to him, so that the translation output may be far from target and/or pragmatically odd. In such cases, C resorts to a word-for-sign translation strategy, ignoring plausibility effects at the sentence level. This effect of the translation task mirrors C's performance in other languages, where the misperception and incorrect translation may be due to a variety of factors: for instance, a spelling similarity between the word to be translated 
and another word in English (see Smith \& Tsimpli I995: I 57ff. for examples). We can thus conclude that the translation data, although interesting for a number of reasons, do not give a completely clear indication of C's underlying knowledge of the grammatical or lexical properties of negation.

\subsubsection{Verb agreement morphology}

As described in section 4.2.2 above, verb agreement in BSL has recourse to locations in the sign space as well as to movement inflections. We were interested to see to what extent this aspect of BSL would be accessible to C, keeping in mind his general difficulty with visuo-spatial information in the non-linguistic domain.

In period I when $\mathrm{C}$ was first taught how to use BSL verb morphology to indicate the verb's arguments, he had persistent problems in using the correct directional affix on the verb stem. For example, in trying to copy a verb sign such as HELP, produced by his tutor, which moved from C's location towards his tutor's location to express 'you help me', C instead moved the sign from himself towards his tutor's location, signifying 'I help you'. This difficulty in retaining meaning by adapting the visual dynamics of the sign persisted across several months of exposure to BSL. There was a similar problem in his first uses of pronominal points, where he also produced the mirror image of what he was seeing, rather than adapting the directional affix to reflect the point of view of the signer. Whether $\mathrm{C}$ misunderstood the instruction to 'copy' the tutor's signed sentence and, as a result, copied the reverse subject and object pronominals is unclear. This reversal was systematic rather than random, which makes the idea that $\mathrm{C}$ misunderstood the instruction more plausible. If this is the case, then his referential use of first and second person pronouns is not a matter of his grammar. That learners have problems with 'shifters' (Jakobson I957; cf. Petitto I984) is well-known, though we do not think that $\mathrm{C}$ had problems with the labels for ' $\mathrm{I}$ ' and 'you', as he used them appropriately in his spoken language. It is important to note that the use of pronominal points involves pointing to the location of the referent, rather than grammaticalising a directional affix on the verb.

Throughout period I, C's performance in using spatial locations to anchor signs was limited, and in spontaneous signing he used only five tokens with verb agreement morphology. These inflections were limited to present referent locations, and four of them involved the verb GIVE moving between himself and his teacher as 2 nd person. In this period, then, it appears that $\mathrm{C}$ has not yet begun to use subject and object agreement morphology; instead, the restriction to present referents indicates that his use of different locations is regulated by the actual context rather than by sign space.

In period 2, $\mathrm{C}$ began to produce verb predicates without directional affixes but with correct pronominal points. For example, in copying the sentence 
G. MORGAN, N. SMITH, I. TSIMPLI \& B. WOLL

YOU-TELEPHONE-ME ('You telephone me'), in which the sign TELEPHONE moves from 2nd person to Ist person, $\mathrm{C}$ signed the inscrutable TELEPHONE YOU TELEPHONE, rather than mirroring the signs as in earlier examples. However, in more complex sentences involving 3 rd person locations, $\mathrm{C}$ persisted in copying sign direction, rather than adapting the sign movement to encode the same meaning that he had been asked to repeat, so YOU-TELEPHONE-HIM ('You telephone him'), for instance, was repeated as HIM ME TELEPHONE HIM ('Him, I telephone him').

Other examples during the 2 nd period, where $\mathrm{C}$ used a verb sign with a directional affix to encode agreement, were also tied to present referents. $\mathrm{C}$ did not use locations for non-present referents in the sign space until period 3 .

In his spontaneous signing at this stage, $\mathrm{C}$ attempted to encode agreement with eight different verbs: ASK, TELEPHONE, LOOK, HELP, TEACH, GIVE, PAY and SEE. Although he was now using agreement more widely, he produced mostly ungrammatical sentences. Of eight tokens, three examples omitted the subject affix of the inflection: *ASK-HE ME ('I ask him'), *GIVE-HE ME ('I give him'), *PAY-HE ME ('I pay him'), where the canonical target would have been: ME-ASK-HE ('I ask him'), and so on. It thus seems that the data from copying, as well as the data from spontaneous production in this period, show that agreement morphology is not as yet part of C's BSL grammar. Both reversal of first and second person pronouns and restrictions imposed by the context on the choice of the referents are still evident. Further, in his ungrammatical uses of agreement morphology, C usually signed the subject as a free pronoun at the end of the sentence, whereas object-agreement morphology appeared easier for him.

In period $3, \mathrm{C}$ gave evidence of having grasped the notion of sign space in both his comprehension and production of agreement morphology. After I 3 hours of exposure, he began to use a location to either side of himself to refer to a non-present referent, as in: I-GIVE-HER and I-HIT-HER; and after $\mathrm{I} 5$ hours, he attempted to inflect signs between two abstract grammatical locations in sign space. This was first seen through the use of lexical items, as in: BOY GIVE-someone GIRL 'The boy gave her (something)'; then through the use of his own location, as in: GIRL I-POINT-AT-HIM BOY 'The girl points at the boy'; and finally through the use of two non-present 3 rd person locations, as in: SHE-HIT-HIM '(The girl) hit (the boy)'. The problem with this use of syntactic sign space was that referents had not been previously established before moving a verb towards or from them, giving rise to contextually uninterpretable sequences such as: I-GIVE-HER, I-HITHER. However, at this stage, we think that agreement morphology was gradually becoming part of C's grammar. This claim is supported by two kinds of evidence: first, he produced data which involved the use of nonpresent referents, indicating that sign space, rather than the actual context, was responsible for establishing pronominal points; second, he produced 
data which included both a lexical sign, establishing the subject or object referent, and a pronominal agreement affix on the verb, co-indexed with the established referent. Despite this development, the optionality of either the referents or the agreement morphology in C's production, giving rise to ungrammatical sentences, clearly shows that we cannot yet speak of mastery.

In tests of his comprehension of verb agreement morphology during this period, $\mathrm{C}$ performed at a level comparable to that of other learners, although still at the poor end of the scale. We administered two tests of comprehension: on the simpler of these, subjects were shown signed sentences on video. All the sentences had a verb which moves in BSL to show agreement with the subject and direct object. Each sentence had two referents (e.g. 'John' or 'the students'). After each signed utterance, subjects picked a written English sentence which constituted the more appropriate translation. There were two sentences to choose from, which varied the role the referents took as subject or direct object. On this task, the comparator group scores were between $60 \%$ and $100 \%$ (SD I $3.3 \%$ ); C scored $60 \%$ correct (chance was $50 \%$ ). In a more complex grammaticality judgement test, he answered by simply alternating his response between $\mathrm{A}$ and $\mathrm{B}$, scoring at chance $(50 \%)$, whereas the scores of the comparator group ranged from $40 \%$ to I00 \% (SD I $6.6 \%$ ).

In period 4, C did use syntactic space, but it was difficult to interpret his agreement marking, as previous reference was again not made clear.

By the fifth period of exposure, $\mathrm{C}$ was spontaneously producing simple directional affixes on verbs correctly, indicating that he could reverse the direction of verb movements to preserve the desired meaning, though this ability was limited to simple sentences. Of the total tokens from this period, I9 out of 26 sentences ( $73 \%$ ) involved verb inflections to non-present 3 rd person locations, with little or no other syntactic information in the sentence. However, even at the end of the period of instruction, he characteristically still made the error of mirroring a verb's directional affix in some of his attempts at copying sentences, signing the utterance *ME-HELP-YOU 'I help you' with the opposite intended meaning of 'You help me'.

C's persisting problem reversing first and second person pronouns may be attributable to the means by which reference is established in BSL, viz. indexing. That he appears to have overcome the restrictions imposed by context in the case of 3 rd person referents and uses sign space instead could stem from the input itself. In particular, in the case of first-time pointing to 3 rd person referents not present in the sign space, there is clear evidence that the originally deictic use of pointing is being grammaticalised to establish a referent. In this case, there is no confusion between a gesture and a grammatical function, since the actual space does not include a point that corresponds directly to a referent. On the other hand, in the case of first and second person referents, the deictic function of a pointing gesture to the signer and the interlocutor may be difficult for an adult second language learner to separate from the grammatical use of sign space (see Poizner et al. 
I 987 for discussion). In these cases, $\mathrm{C}$ fails to distinguish pragmatic reference established via gestures from the use of first and second grammatical person, and thus the reversal required in copying tasks proves difficult for him.

By the end of the learning period, $C$ had used sign space correctly with the following agreement verbs: GIVE, ASK, LOOK, HELP, TEACH, PAY, SEE, HIT, BLAME, THROW, PAINT, FEED, TELEPHONE and INVITE.

As with the use of negation markers, we assessed the limits of C's understanding of agreement morphology by getting him to translate into English BSL sentences which involved more complex verb morphology. As with negation, his intermittently incorrect processing of signs and his limited short-term memory for long sentences made this task difficult for him, and he correctly identified only I out of 6 sentences, (2od). The examples of his mistranslations in (20) illustrate the difficulty provided by sentential complexity. For instance, $\mathrm{C}$ was well aware of the form of the sign TELEPHONE, and also that it could be moved around sign space to indicate the relevant arguments, yet he mistranslated it, with devastating effect on the overall meaning.

(20) (a) A: STUDENT ++ cl-MANY-PERSON ${ }_{\mathrm{a}}$ TEACHER TEACH 'The teacher teaches the students.' C: Students sit at the teacher's desk.

(b) A: $\overline{\text { RED CAR }}_{\mathrm{a}}^{\mathrm{t}}$ cl-CAR-DRIVE-PAST LOOK
'I watched the red car drive past.'
$\mathrm{C}$ : The red car is in the road.

(c) A: b-i-l-1 IX $\mathrm{a}_{\mathrm{a}} \mathrm{j}$-o-h-n IX I $_{\mathrm{a}}$ TEACH $_{\mathrm{b}}$ GREEK SATURDAY 'Bill teaches John Greek on Saturday.'

C: Bill and John eat Greek food on Saturday.

(d) A: MORNING s-a-1-l-y a SHE-TELEPHONE-US 'Sally telephoned us this morning.'

$\mathrm{C}$ : Sally $\operatorname{ran}(\mathrm{g})$ in the morning.

(e) A: CAT IX CHILDREN $_{b}{ }_{b}$ THEY-LOOK-DOWN 'The children look at the cat.'

$C$ : The cat pushed children away.

(f) A: LAST-NIGHT FATHER HE-TELEPHONE-ME 'My father telephoned me last night.'

C: Father had a cup of tea last night.

The errors in (20c) and (2of) can be explained on the basis of the phonological similarity between the pairs of signs EAT and TEACH, and TELEPHONE and TEA. For instance, the sign TELEPHONE shares its 
place of articulation and part of its hand-shape with the sign TEA. As discussed in the previous section, translation data impose additional problems on C's processing of the BSL input, and cannot be assumed adequately to reflect his competence in his developing grammar.

\subsubsection{Questions}

Across the five periods $\mathrm{C}$ used the question signs WHAT, WHERE and WHEN regularly but, apart from one example, he did not use accompanying facial-action with questions. The incidence of C's use of questions in his spontaneous signing is shown in table 2 , which includes the total number of

\begin{tabular}{llllll}
\hline Time period & $\begin{array}{l}\mathrm{PI}_{15} \\
{[\mathrm{n}=\mathrm{I} 5]}\end{array}$ & $\begin{array}{l}\mathrm{P}_{2} \\
{[\mathrm{n}=7]}\end{array}$ & $\begin{array}{l}\mathrm{P}_{3} \\
{[\mathrm{n}=0]}\end{array}$ & $\begin{array}{l}\mathrm{P}_{4} \\
{[\mathrm{n}=\mathrm{I} 8]}\end{array}$ & $\begin{array}{l}\mathrm{P}_{5} \\
{[\mathrm{n}=\text { I4] }}\end{array}$ \\
\hline Wh & $\mathrm{I} 3$ & 4 & 0 & 9 & $\mathrm{I} 3$ \\
Yes/No & 2 & 3 & 0 & 9 & $\mathrm{I}$ \\
\hline
\end{tabular}

Table 2

Christopher's use of different question forms in BSL

utterances used with a question function and expressed either through the use of a question sign (Wh- interrogatives) or through sign order (Yes-No interrogatives).

In the first class of period I, $\mathrm{C}$ had to repeat short sentences offered to him by a deaf signer (FE), as illustrated in (2I). As these were Wh- questions, FE used a furrowed brow (bf) simultaneously with the signs. As before, the horizontal line shows the scope of the Wh- marker across the manual signs.

(2I) (a)

FE: HELLO NAME $\overline{\text { YOU WHAT }}$

'Hello, what's your name?'

(b) C: HELLO NAME ME WHAT

'Hello, what's my name?'

It is crucial to note that $\mathrm{C}$ was not asked to answer the question, but was supposed to repeat the sentence verbatim. It is characteristic of BSL classes at this level to be taught like this, with attempts made to shape the students' signing. Interestingly, $\mathrm{C}$ did not point away from himself to indicate 'YOU', but pointed at himself, 'ME', copying the direction rather than the meaning of the personal pronoun (see previous section). We cannot, of course, be 
certain that $\mathrm{C}$ was attempting to carry out the instruction 'Now you do the same' correctly. More strikingly, in the first period of sign exposure, he made no accompanying change in the facial-action needed to signal questions. Despite these inadequacies, he did put the Wh- sign correctly at the end of the sentence, though this might have been formulaic, as his response a few minutes later to 'maybe ask Frances now' was the ungrammatical WHAT NAME YOU NAME - 'What's your name, name?'. However, when he was asked in English about the order of the signs he had used (by two of the authors, BW and NS), he replied correctly, as shown in (22), and generalised the pattern to new question types, as in the correct (23).

(22) (a) NS: 'What order did you do the signs in?' C: NAME ME CHRIS

(b) BW: 'Can you remember the order for questions?'

$$
\begin{aligned}
& \text { C: YOU NAME WHAT } \\
& \text { C: YOU HOW-OLD YOU } \\
& \text { 'How old are you?' }
\end{aligned}
$$

Looking in more detail at the questions used in period I, it seems that although $\mathrm{C}$ used Wh- signs appropriately in the copying tasks, many examples of questions produced in spontaneous signing were articulated without a Wh- sign. Again, as with negation, C relied on the context to make himself understood. For example, after being asked his age, he attempted to ask the same question, but only managed to sign: AGE YOU; a sequence which, in an appropriate context, would be an interpretable question in BSL. In fact, most of his putative Wh- questions produced without Wh- signs were correctly interpreted by his interlocutor. Other examples were: AGE YOU WIFE YOU '(What is) your wife's age?'; YOU SPORT YOU '(What) sport do you (do)?'; and when asked about which languages he knew, $\mathrm{C}$ tried to ask the same question with: LANGUAGES YOU; presumably, '(Which) languages do you (know)?'.

We have not included such sentences in the figures in table 2, and as far as C's performance in Wh- questions including Wh- markers is concerned, it appears that he intuited the sentence-final position of the Wh- sign right from the beginning. Moreover, he was consciously aware of the relevant ordering rule, as his responses in (22) indicate. Despite this, his own production of Wh- signs shows that the sentence-final position is not part of his grammar at this early stage, since he spontaneously produces English-like order in BSL Wh- questions. The total absence of facial expression accompanying the sign sequence is consistent with the general lack of intonational and facial features attested in his spoken languages. It is important to note that $\mathrm{C}$ does pick up on some facial grammar in his comprehension (e.g. questions and negation markers), but there is a complete absence of facial expression in his production. This parallels contexts of non-signing, where he shows a 
comparable lack of facial expression, though we are ignorant of the ultimate reason for this.

Across periods 2 and 3, there were few examples of spontaneously produced questions, and in general he used question syntax inconsistently. He often appeared to ask questions omitting the relevant signs, such as: BROTHER YOU '(Do) you (have) a brother?'. He had been asked previously if he had brothers or sisters, and his signed sequence here was therefore plausibly interpreted as 'Do you have a brother?'. In none of these examples did he make any recognisable use of facial-action to signal the question function.

In period 4, after I 5 hours of sign exposure, we observed considerably more signed sentences involving question forms ( 18 tokens). Of the 9 examples of Wh- questions, 7 included correct BSL ordering, i.e. a questionfinal Wh- sign. The remaining 2 examples were produced with the Wh- sign in the middle of the sentence, as in AGE WHAT YOU. This may be due in part to the fact that YOU often occurs in sentence-final position as an indication that the signer is relinquishing his or her turn. Although not included in the analysis, there were 15 other examples of putative questions articulated without a Wh- sign. It is significant that in this period none of the nine Wh- questions had a Wh- sign in initial position: that is, none had the word order characteristic of English questions, though there were some occurrences of initial Wh- in his spontaneous signing. Wh- signs can occur initially in BSL, but when they do there is usually another Wh- marker at the end of the sentence.

The complexity of his question forms also became gradually more sophisticated. After I6 hours of BSL, C asked his sign tutor: YOU MOTHER FATHER LIVE '(Where) do your mother and father live?'; and after I9 hours, he asked: MAN BEARD NAME WHAT 'What's the man with the beard's name?'. It was in this period that we observed C's only use of facial-action for question asking. After his tutor had spoken about her father, $\mathrm{C}$ asked:

\section{BALD}

'Is (he) bald?'

In period $5, \mathrm{C}$ continued to use the correct sign order in the majority of his sentences with Wh- signs, but persisted in asking the majority of all questions without question signs. This reliance on the pragmatic context was marked, as is indicated in (25)-(26).

(25) (a) A: LIVE YOU WHERE 'Where do you live?'

(C replies to the question then asks:)

(b) C: YOU LIVE '(Where) do you live?'

(The 'question' receives an appropriate answer.) 
G. MORGAN, N. SMITH, I. TSIMPLI \& B. WOLL

(26) (a) A: WORK YOU WHAT

C: WORK YOU

(b) A: MOTHER YOUR BORN WHEN

C: FATHER YOU BORN

Although $\mathrm{C}$ produced multi-sign questions, the subject matter was often repetitious but, overall, his development of sign-order in questions was quite good. In the majority of cases where the Wh- sign is required, $\mathrm{C}$ used it appropriately in sentence-final position so transfer effects, especially in periods 4 and 5, are not found. On the other hand, his frequent omission of the Wh- sign is interesting and problematic at the same time. It is interesting in that $\mathrm{C}$ (consciously or not) relies on his interlocutor to exploit the context to interpret the sentence as a Wh- question. This results in his producing elliptical utterances which are acceptable in an appropriate context, just as the omission of Wh- phrases in spoken languages is acceptable in specific registers and contexts. It is noteworthy that his failure to use Wh- signs is not evidence of his lack of the relevant linguistic knowledge, since he produced them appropriately in Wh- questions during the same periods that he produced questions without them. Thus, the omission cannot be the result of either lack of lexical knowledge of the Wh- sign or of its syntactic distribution. Furthermore, the pattern of omissions seems to involve the Whsign rather than other lexical signs in the question, making it difficult to motivate an explanation in terms of processing load. However, it is worth recalling that an additional requirement of target Wh- questions is a particular facial expression: specifically, a furrowed brow. This facial expression, with its starting point preceding the Wh- sign, reinforces the Whsign in sentence-final position. We can then tentatively suggest that, by omitting the Wh- sign, $\mathrm{C}$ makes the task of repeating and spontaneously producing Wh- questions easier for himself. This is not due to the production load associated with the Wh- sign itself, but to the avoidance of the obligatory facial expression accompanying the sign. Since facial expressions are clearly problematic for $\mathrm{C}$, and there is additional evidence throughout the learning period of his inability to use them to mark Yes-No questions, it is plausible that his omission of the Wh- sign is a function of its necessary association with a facial expression. This would be consistent with our previous claim about C's misanalysis of the head-shake in negatives as being a morphological rather than a suprasegmental feature, indicating scope over the manual sequence of signs in the same sentence.

Finally, when $\mathrm{C}$ was asked to translate novel questions he was less successful: of I3 question sentences in BSL, he translated only one accurately: 'How old are you?'. He recognised a question function in four others but failed to recognise the question at all in five sentences. The remaining examples he didn't attempt to translate. This drop in performance in translation tasks involving questions is consistent with his translation of 
negative sentences and those involving verbs with agreement morphology discussed in previous sections.

\section{$5 \cdot 3$ Achievements}

By period 5, C's signing had greatly improved and was at a level where he could conduct a simple conversation. However, the complexity of manipulating locations in sign space was still not consolidated, and he used real world objects and locations (including himself and his interlocutor) to map out sign modifications. Although his sign formation had improved, other aspects of sign, such as more complex verb inflections, were intermittently missing. Thus after 24 hours' exposure to BSL over a period of somewhat more than a year, $\mathrm{C}$ was still largely limited to using real world locations. It is difficult to determine whether this is a function of his limited ability to manipulate configurations of signs, or to handle connected discourse in general; that is, whether his limitations were BSL-specific or languageindependent. $\mathrm{C}$ finds constructing monologues and connected discourse generally difficult, as is evident from his spoken languages including English. We have previously suggested (Smith \& Tsimpli I995: 67, I64ff.) that $\mathrm{C}$ has difficulty in participating in connected discourse because of his mildly autistic status.

An impression of his achievement can be derived from the extract in (27), taken from one of C's classes towards the end of his exposure to BSL (after approximately 20 hours). An examination of part of this 6.35 minute exchange between $\mathrm{C}$ and his tutor shows that he has made radical improvements in signing. In almost all of this exchange, $\mathrm{C}$ maintained appropriate eye-gaze towards his interlocutor (looking at her lower face and torso) while she was signing, and he periodically checked for comprehension when he was signing himself.

(27) Context: $\mathrm{C}$ is seated at a table waiting for Anne (A) to arrive, when she enters. ${ }^{9}$

[9] Translation and comments C: Hello, here, hello A: Hello are you well? C: I'm well, Anne-finger-spells (fs) A: Yes C: Chris (fs) A: Yes C: There's the bag A: There is nothing C: A book A: So where do you live? C: Malton (fs) Where do you live? A: Norton C: Norton, you are signing A: Sign? C: Signing, work with you A: My work? I'm a teacher C: Teacher A: I work as a teacher, what do you work as? C: Over there A: What do you do? C: Separating out wool A: Like it, do you like it? C: I like it, I do, do you like your work? A: I like my teaching job, I like teaching, I work in a factory but I don't like that C: Factory A: Yes a factory, I work a sewing machine by hand C: By hand A: Yes a sewing machine C: A sewing machine A: Yes that's my job C: My job, do you cook? A: Cook? Have you eaten? C: Eaten, your book over there A: What did you have for dinner? C: I ate 
G. MORGAN, N. SMITH, I. TSIMPLI \& B. WOLL

C: HELLO HERE (pointing to a spare chair at the table) HELLO

A: HELLO WELL-YOU

C: WELL a-n-n-e

A: YES

C: c-h-r-i-s

A: YES

C: points towards tutor's bag indicating he wants to see what is inside

A : NOTHING

C: BOOK

A: YOU LIVE WHERE

C: m-a-1-t-o-n YOU LIVE WHERE

A: n-o-r-t-o-n

C: n-o-r-t-o-n SIGN YOU (no use of question intonation on the face)

A : $\overline{\mathrm{SIGN}}$

bf

C: SIGN WORK YOU

A: WORK ME TEACHER ++ (demonstrates sign repeatedly)

C: TEACHER

A: WORK TEACHER YOU WORK WHAT

$\mathrm{C}$ : points towards bag for second time

A: WHAT

C: WOOL-SEPARATING (looking at A while signing)

A : $\overline{\text { LIKE }}^{\mathrm{YOU} \text { LIKE }}$

C: LIKE ME LIKE WORK ME YOU LIKE YOU WORK

hn
A: ME LIKE TEACH ME WORK LIKE TEACH ME WORK FACTORY
NO-LIKE ME (C looks at Anne throughout this interchange)

\footnotetext{
A: But what? Where did you eat C: I ate here A: Over there C: There A: Do you cook? C: Cook, no I don't cook, do you cook? A: Me, yes I cook dinner for my family, and you? C: The work book over there A: Yes C: Your work book A: Norton (fs) C: You work in Norton (fs) A: My factory work C: That's right A: I work in a factory (fs) C: Factory A: Factory C: The bag there A: It's cold outside: C: Outside it's cold A: It's raining C: It's raining A: Do you like the rain? C: I like the rain and you? A: No I don't like the rain $\mathrm{C}$ : I like it A: I like the sun C: The sun A: Hot weather C: Hot weather A: Do you like it? C: Hot weather and rain, there the bag A: So you want to do some work then? C: That work there A: OK then C: OK then A: Oh, where's Erich (fs) Erich where is he? C: He's German, away A: He's not coming? C: He's up there A: Upstairs, sleeping? C: The bag over there A: $O K$
} 
$\mathrm{C}$ : FACTORY (trying to produce the sign)

A: FACTORY

C: $\overline{\text { FACTORY }}$

addressee

A: ME USE-SEWING-MACHINE TURN-MACHINE-BY-HAND

C: TURN-MACHINE-BY-HAND

addressee

A: USE-SEWING-MACHINE

C: $\overline{\text { USE-SEWING-MACHINE }}$

addressee

A: WORK ME

C: $\overline{\text { WORK ME YOU COOK }}$ br

A: $\overline{\operatorname{COOK}}$ (correcting sign) addressee

C: EAT YOU BOOK THERE (points to tutor's bag for third time)

A: YOU DINNER WHAT YOU

bf

C: ME EAT

A: WHAT WHERE

C: EAT HERE (points to table where they are both seated)

A: THERE (points to direction of dining room)

C: THERE (points to direction of dining room)

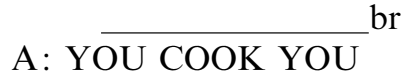

addressee

addressee

C: COOK COOK $\overline{\text { NOT-ME }}^{\text {neg }}$ YOU COOK (touches teacher's shoulder)

A: ME COOK DINNER MY FAMILY YES YOU

C: WORK THERE (points to tutor's bag for fourth time)

A: YES

C: $\overline{\text { YOU WORK BOOK }}$

addressee

A: n-o-r-t-o-n

C: $\overline{\text { YOU WORK }}_{\text {n-o-r-t-o- }}^{\text {addressee }}$

A: MY WORK FACTORY

C: GOOD (smiling at recognition of sign)

A: ME WORK f-a-c-t-o-r-y

C: FACTORY 
G. MORGAN, N. SMITH, I. TSIMPLI \& B. WOLL

A: FACTORY (correcting sign, she turns her hands to show $Y$ handshape more clearly)

$\mathrm{C}$ : (C offers his hands to tutor so she can try to shape them into $\mathrm{Y}$ hand-shapes, he cannot extend his thumb and little finger at the same time. Tutor changes sign to an A hand-shape; C performs the modified sign like this.) FACTORY THERE (points towards the bag for the fifth time)

A: OUTSIDE COLD

C: COLD OUTSIDE

A: RAIN ++

C: RAIN (looking outside)

A. $\overline{\text { YOU LIKE RAIN }}^{\text {br }}$

addressee

C: ME LIKE RAIN YOU (touches tutor's shoulder)

A: NO NO-LIKE RAIN

C: LIKE

A: ME LIKE SUN

C: SUN

A: HOT

C: HOT

A: YOU LIKE

C: HOT RAIN THERE (points to bag for 6th time)

A: YOU WANT WORK br

C: WORK THERE (points to bag)

A: GOOD

$\mathrm{C}$ : GOOD ( $\mathrm{C}$ is visibly pleased he has finally got his message across but A quickly returns without the books)

$$
\text { bf bf }
$$


normally takes the class with $\mathrm{C}$ )

C: e-r-i-c-h GERMAN 'Scotland' (whispering)

A: e-r-i-c-h

$\mathrm{C}$ : (C tries to explain that he isn't here) AWAY (starts to draw a map on the table)

A: $\overline{\text { NOT-COME }}$

C: UP (perhaps indicating the North)

A: $\overline{\text { SLEEPING UPSTAIRS }}$

C: (points back to bag)

A: OK

$$
\text { br }
$$


$\mathrm{C}$ : shows frustration at not being able to sign Scotland (he has used this sign several times before)

A number of observations are in order: first, $\mathrm{C}$ appears to understand all the BSL produced by his conversational partner; second, he happily initiates questions; third, he is making progress with sign order, in that it appears that he has acquired the topicalised sentence pattern of BSL, even if his use of it is not entirely consistent. The overall coherence of this discourse is not markedly dissimilar from that of his English conversation: see e.g. Smith \& Tsimpli (I995: 67-69).

\section{DiscuSSION: THE UPTAKE OF BSL}

It is apparent that $\mathrm{C}$ has begun to master BSL. In all three aspects that we were initially interested in (lexicon, grammar and communication) he has made significant developments. He has learnt an impressive number of signs, more evidently in his comprehension than in his production. He is able to construct simple sentences involving grammatical BSL constructions for negation, verb agreement and question formation. He has developed those communicative devices necessary for face to face communication with deaf people in BSL, namely, looking at the signer, signalling to the watcher before signing, and checking for comprehension when signing. On the basis of this, we suggest that the original prediction that C's linguistic talent would outweigh the disadvantages of the medium in which BSL is produced has been borne out.

On the other hand, the visuo-spatial nature of sign language, and the absence of a written script, have caused problems for $\mathrm{C}$, as seen in his less proficient learning of BSL vis-à-vis other spoken languages. His apraxia has meant that some signs and sign modifications have been impossible for him to articulate, and there are still areas of BSL which are beyond him. In translation from BSL to English, his performance drops due to the requirements of the task, a phenomenon also found in his translation between spoken languages.

It is clear that C treats BSL as a language. He rarely if ever spoke and signed at the same time, and he separated English and BSL from his first day of exposure. But his learning has been limited to areas of BSL where sign space plays a subsidiary role. He has to a large extent mastered the nonmanual markers of negation, but combining a head-shake with other signs is a major chore for him. These difficulties in combinations include cooccurrence in the same sentence, rather than simultaneous production as in the target language. His misanalysis of the head-shake as a morphological rather than a supra-segmental feature, and its use either as an anaphoric negator or as a sentential negator, illustrate C's morphology-oriented language development, shown in other languages for which the input was 


\section{G. MORGAN, N. SMITH, I. TSIMPLI \& B. WOLL}

controlled, viz. Berber and Epun (Smith et al. 1993, Smith \& Tsimpli I995). Furthermore, $\mathrm{C}$ has acquired BSL question-final syntax, even though he does not use the accompanying facial-action with question signs. We have argued that the omission of the Wh- sign in sentence-final position could be a sideeffect of the obligatory presence of the facial expression used in questions, which appears to be largely beyond C. Finally, the BSL verb morphology system, which requires complex use of sign space, has been partially but not fully mastered. C relies on real world locations and, to a lesser extent, on a non-present referent location to his side for 3 rd person referents. The interaction between sign space and morpho-syntax needed to encode more complex predicates does not appear in his own signing and is also understood less well, as is seen in the results of tests of copying and translation. In the copying tasks, a gradual development in the use of verb-agreement morphology is attested, although omission of either the lexical sign for the referent or one of the agreement affixes is found even in data from period 5 .

Bearing in mind the discussion of verb agreement, the fact that C's development of BSL morphology appears delayed compared to that in his other, spoken, languages is probably attributable to the following reasons:

(i) the fact that the marking for first and second person is ambiguous between a gestural and a grammatical function;

(ii) the absence of a written version of BSL sentences, which reduces his ability to retain in memory abstract morphological regularities that he could then apply and (over)generalise to all verbs; and

(iii) the lexically restricted nature of verb-agreement morphology in BSL, which does not apply to all verbs in the language.

Thus, although $\mathrm{C}$ has found vocabulary learning relatively simple, he has not shown comparable facility with the parts of BSL morphology tied to verb agreement. Furthermore, although C's signing is fairly limited in terms of length of utterance, it is striking that, with BSL questions, he does not use English syntax. That is, the transfer effects clearly found in the syntax of his other non-native, spoken, languages are not as evident in BSL. It may be that the reason why Li transfer is not obvious in C's BSL has to do with the distinct modality of the language: in particular, the contrast between the signed and the spoken input may have an inhibitory effect on transfer strategies, which we have found in almost all aspects of C's L2 syntax.

$\mathrm{C}$ has not learnt a language comparable to BSL before, and we may have put him at a severe disadvantage by (inevitably) taking away the written script which normally accompanies the languages he has learnt. $\mathrm{C}$ has at his disposal a huge stock of (orthographic) representations of lexical items from a wide variety of spoken languages. These clearly allow him to 'cross-refer' in a way that maximises learning and recall efficiency. Such cross-referencing is extremely limited for BSL because of the absence of any orthographic 
medium. For example, in period 3, $\mathrm{C}$ failed to recognise the meaning of the sign LONDON. This sign was used several times during the course, and $\mathrm{C}$ has used it himself several times. However, for some reason he is unable to retain a memory trace for this sign, which is made up of the index finger making small circles next to the ear. It is clear that $\mathrm{C}$ has difficulty making the connection needed to link this sign to its meaning. That is, his memory store for gestural information is less developed than his store for orthographic information.

\section{Conclusions}

We are left with the puzzle that $\mathrm{C}$ has acquired several aspects of BSL to the level of a normal learner, but performs very poorly on other aspects. In performance, his apraxia can explain some of these difficulties. He cannot produce co-ordinated facial-actions and signs, but he demonstrated good comprehension of questions and negation, even though he finds verbal morphology beyond that of the simple sentence difficult to process. That is, he understands questions addressed to him, and in his own signing he produces many questions with correct BSL syntax. The residual processing difficulty may be a result of a memory deficit for rapidly changing visual information, or the influence of his deficits in non-verbal visuo-spatial cognition. This remark may seem to be at variance with the fact that $\mathrm{C}$ is quite proficient at finger-spelling. However, it is important to note that finger-spelling is a representation of English and is an example of a very simple and over-learned code. When he sees finger-spelled words, $\mathrm{C}$ is simply 'reading' in a transduction of his first language.

A final question relates to the analysis of BSL. Can morphology in BSL be analysed similarly to morphology in spoken language? In this paper we have suggested some differences and similarities between verb-agreement morphology and the means of establishing reference in BSL and spoken languages. Similarly, in negatives and interrogatives, the interaction of facial expression and manual signs has been argued to differ in some respects from what occurs in spoken languages. Further investigation of this and other morphological aspects of BSL is required in order to address the question of C's developmental picture in BSL and compare it with the learning patterns he has shown in other, spoken, languages.

At this point in our analysis we have demonstrated that $\mathrm{C}$ has learned BSL to a degree which supports the prediction that knowledge of language is largely, but not entirely, modality independent. We have also demonstrated that he did indeed find BSL linguistically satisfying. Considering his physical and psychological profile, and the special nature of sign language, this learning is remarkable. Definitive explanations for his particular successes and failures will require further exploration of both BSL and C's unique talent. 


\section{APPENDIX}

\section{Schedule of classes}

I. Introduction to signing. Naming, questions and finger-spelling.

2. Wh- and yes-no questions. Simple naming questions, asking about work, family, foods. Vocabulary and practice.

3. Negation markers in different syntactic constructions.

4. Verb agreement through different morphological modifications of the sign. Vocabulary and practice.

5. Using classifiers and sign space. Using facial expression.

6. Review of previous topics and practice.

7. Narratives with two characters, classifiers, sign space and role shift.

8. Using topic markers in simple sentences, simple verb aspect markers.

9. Question and negation with new verbs, finger-spelling.

Io. Verb agreement with locations in sign space.

I I. Narrative with three characters.

I2. Complex sentences.

\section{REFERENCES}

Baron-Cohen, S. (1995). Mindblindness. Cambridge, MA: MIT Press.

Battison, R. (1978). Lexical borrowing in American Sign Language. Silver Spring, MD: Linstok Press.

Brennan, M. (1990). Word formation in British Sign Language. Ph.D. dissertation, University of Stockholm.

Brennan, M. (1992). The visual world of BSL: an introduction. In Brien, D. (ed.), Dictionary of British Sign Language/English. London: Faber \& Faber. I-I 34.

Chomsky, N. (1995). The Minimalist Program. Cambridge, MA: MIT Press.

Engberg-Pedersen, E. (1995). Point of view expressed through shifters. In Emmorey, K. \& Reilly, J. (eds.), Language, gesture and space. Hillside, NJ: Lawrence Erlbaum Associates I33-I 54 .

Goodglass, H. \& Kaplan, E. (1972). The assessment of aphasias and related disorders. Philadelphia: Lea and Febiger. [Revised edition, I983.]

Jakobson, R. (1957). Shifters, verbal categories and the Russian verb. Cambridge, MA: Harvard University Press.

Kimura, D. (1982). Left hemisphere control of oral and brachial movements and their relation to communication. Philosophical Transactions of the Royal Society of London, Series B, 298. I 35 -I 49 .

Klima, E. \& Bellugi, U. (1979). The signs of language. Cambridge, MA: Harvard University Press.

Liddell, S. \& Johnson, R. (I989). American Sign Language: the phonological base. Sign Language Studies 64. 195-277.

Morgan, G. (I999). Event packaging in British Sign Language discourse. In Winston, E. (ed.), Story telling and conversation: discourse in deaf communities. Washington, DC: Gallaudet University Press. $27-58$.

Morgan, G., Smith, N. V., Tsimpli, I.-M. \& Woll, B. (2002). The effects of modality on British Sign Language development in an exceptional learner. In Meier, R., Cormier, K. \& Quinto, D. (eds.), Modality and structure in signed and spoken languages. New York: Cambridge University Press.

Morgan, G., Smith, N. V., Tsimpli, I.-M. \& Woll, B. (in preparation). BSL learning in talented language learners. 
Neidle, C., Kegl, J., MacLaughlin, D., Bahan, B. \& Lee, R. (2000). The syntax of American Sign Language: functional categories and hierarchical structure. Cambridge, MA: MIT Press.

O'Connor, N. \& Hermelin, B. (I99I). A specific linguistic ability. American Journal of Mental Retardation 95. 673-680.

O'Connor, N., Smith, N. V., Frith, C. \& Tsimpli, I.-M. (I994). Neuropsychology and linguistic talent. Journal of Neurolinguistics 8. 95-107.

Petitto, L. A. (I984). On the autonomy of language and gesture: evidence from the acquisition of personal pronouns in ASL. Cognition 27. 83-I05.

Pizzuto, E., Giuranna, E. \& Gambino, G. (I990). Manual and non-manual morphology in Italian Sign Language: grammatical constraints and discourse processes. In Lucas, C. (ed.), Sign language research, theoretical issues. Washington, DC: Gallaudet University Press. 83-I02.

Poizner, H., Klima, E. \& Bellugi, U. (1987). What the hands reveal about the brain. Cambridge, MA: MIT Press.

Smith, N. V. (I996). A polyglot perspective on dissociation. Behavioural and Brain Sciences $\mathbf{1 9 .}$ 648.

Smith, N. V. \& Tsimpli, I.-M. (I99I). Linguistic modularity? A case-study of a savant linguist. Lingua 84. 3I 5-35I.

Smith, N. V. \& Tsimpli, I.-M. (I993). A specialist intelligence: the case of a polyglot savant. In Harris, J. (ed.), UCL Working Papers in Linguistics 5. London: UCL. 4I 3-450.

Smith, N. V. \& Tsimpli, I.-M. (I995). The mind of a savant: language learning and modularity. Oxford: Blackwell.

Smith, N. V. \& Tsimpli, I.-M. (I996). Putting a banana in your ear. Glot International 2.I/2. 28

Smith, N. V. \& Tsimpli, I.-M. (I997). Reply to Bates. International Journal of Bilingualism 2. I $80-186$.

Smith, N. V., Tsimpli, I.-M. \& Ouhalla, J. (I993). Learning the impossible: the acquisition of possible and impossible languages by a polyglot savant. Lingua 9I. 279-347.

Stokoe, W. (1960). Sign Language structure: an outline of the visual communication of the American deaf (Studies in Linguistics Occasional Papers 8). Buffalo, NY: University of Buffalo, Department of Anthropology and Linguistics.

Sutton, V. (1999). Sign Writing: on the occasion of its 25th anniversary. Sign Language and Linguistics 2.2. $27 \mathrm{I}-282$.

Sutton-Spence, R. L. \& Woll, B. (I999). An introduction to the linguistics of BSL. Cambridge: Cambridge University Press.

Tsimpli, I.-M. \& Smith, N. V. (I993). LF and post-LF in a polyglot savant's grammars. In Tsimpli, I. (ed.), Newcastle and Durham Working Papers in Linguistics I. Newcastle: University of Newcastle. 276-29I.

Tsimpli, I.-M. \& Smith, N. V. (I995). Minds, maps and modules: evidence from a polyglot savant. Working Papers in English and Applied Linguistics 2. Cambridge: University of Cambridge Research Centre for English and Applied Linguistics. I-25.

Tsimpli, I.-M. \& Smith, N. V. (I998). Modules and quasi-modules: language and theory of mind in a polyglot savant. Learning and Individual Differences I0. I93-2 I 5.

Warrington, E. K. (1984). Recognition Memory Test. Slough, UK: National Foundation for Education Research, Nelson Publishing Co.

Authors' address: Department of Language and Communication Science, City University, London, Northampton Sq. London ECI VoHB, U.K.

E-mail:g.morgan@city.ac.uk 